\title{
Evaluation of Patient and Medical Staff Satisfaction regarding Healthcare Services in Wuhan Public Hospitals
}

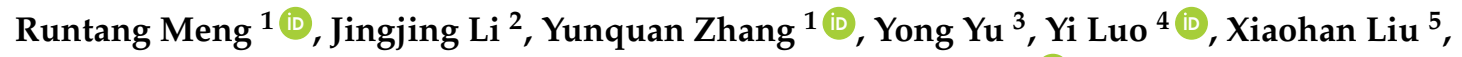 \\ Yanxia Zhao ${ }^{5}$, Yuantao Hao ${ }^{5}$, Ying Hu ${ }^{1,6}$ and Chuanhua Yu ${ }^{1,6, * \text { (iD) }}$ \\ 1 Department of Preventive Medicine, School of Health Sciences, Wuhan University, 185 Donghu Road, \\ Wuhan 430071, China; mengruntang@whu.edu.cn (R.M.); Yun-quanZhang@whu.edu.cn (Y.Z.); \\ huy@whu.edu.cn (Y.H.) \\ 2 Department of Behavioral Sciences and Health Education, Rollins School of Public Health, Emory University, \\ 1518 Clifton Rd.NE, Atlanta, GA 30322, USA; Jingjing.li@emory.edu \\ 3 School of Public Health and Management, Hubei University of Medicine, 30 South Renmin Road, \\ Shiyan 442000, China; Andyook@21cn.com \\ 4 School of Nursing, Ningbo College of Health Sciences, 51 Xuefu Road, Ningbo 315100, China; \\ royeelove@163.com \\ 5 Department of Medical Statistics and Epidemiology, Guangdong Key Laboratory of Health Informatics, \\ Health Information Research Center, School of Public Health, Sun Yat-Sen University, 74 Zhongshan Rd.2, \\ Guangzhou 510080, China; liuxiaohan51@163.com (X.L.); sptmg_d@163.com (Y.Z.); \\ haoyt@mail.sysu.edu.cn (Y.H.) \\ 6 Global Health Institute, Wuhan University, 8 South Donghu Road, Wuhan 430072, China \\ * Correspondence: yuchua@whu.edu.cn; Tel.: +86-27-6875-9299
}

Received: 28 March 2018; Accepted: 13 April 2018; Published: 17 April 2018

\begin{abstract}
Satisfaction evaluation is widely used in healthcare systems to improve healthcare service quality to obtain better health outcomes. The aim of this study was to measure employee work satisfaction and patient satisfaction status in Wuhan, China. A cross-sectional study was conducted in 14 medical institutions. The final valid sample comprised a total of 696 medical staff and 668 patients. The overall satisfaction levels of medical staff and patients were $58.28 \pm 14.60(10.47-100.00)$ and $65.82 \pm 14.66$ (8.62-100.00), respectively. The factors affecting medical staff satisfaction, ranking in sequence from most to least satisfied, were: the work itself, working environment and atmosphere, hospital management, practicing environment, and job rewards. Patient satisfaction factors, from most to least affecting, were ranked as follows: physician-patient relationship and communication, service organization and facilities, continuity and collaboration of medical care, access to relevant information and support, and healthcare and related services, respectively. The overall satisfaction evaluation of medical staff was average. Healthcare policy makers and medical institution management staff should focus on job rewards and working environment. This would allow them to increase their work happiness and sense of belonging, which in turn would allow them to provide better medical services to patients. The overall patient evaluation was satisfactory, with patients satisfied at all levels of the satisfaction evaluation.
\end{abstract}

Keywords: Chinese health care reform; satisfaction; medical staff; patient; coping strategy; health management and policy

\section{Introduction}

For a long time, work satisfaction has been a core concept of organizational behavior and has been used to measure the attitudes of proactivity or happiness towards work in employees, based on employees' evaluation of work characteristics (work experience). Furthermore, work satisfaction 
is an important marker of whether or not a corporation's reward mechanism is successful [1]. The work satisfaction of medical staff (doctors, nurses, medical technicians, etc.) is related to healthcare service quality and outcomes. Low satisfaction is a major cause of psychological and social stress in medical staff and correspondingly of employee turnover [2-5]. Many studies have demonstrated that healthcare staff with high satisfaction provide higher quality medical services, resulting in better healthcare outcomes and higher patient satisfaction [6-9]. On the other hand, patient satisfaction comprises patients' overall evaluation of the entire healthcare service process and consultation environment, and is a commonly used and key indicator for evaluation of healthcare service quality $[10,11]$. Analysis of patient satisfaction survey feedback results can provide healthcare workers with sufficient understanding of factors and areas that require improvement and can lead to effective improvements in medical service quality [12,13]. Systematic studies have verified that the medical service quality indicator is the determining factor that has the most influence on patient satisfaction. Another indispensable determining factor is healthcare providers' interpersonal care quality [14]. At the same time, healthy interactions between medical staff and patients are extremely important and can improve both the physician-patient relationship [15] and nurse-patient relationship [16]. This can encourage medical staff to improve their work efficiency and medical service quality [17] and can also promote patient recovery [18]. In China, tense physician-patient and nurse-patient relationships, insufficient mutual communication, and poor understanding are important factors causing dissatisfaction.

Currently, there are many tools to measure medical staff satisfaction and patient satisfaction worldwide $[19,20]$. Each tool has its own characteristics, target population, and usage focus, and they are not completely uniform. Tools for measuring work satisfaction in medical staff include universal scales (such as those used for all service staff [21], healthcare service staff [17,22], etc., and specific scales (such as those used for hospital doctors [23,24], hospital nurses [25], dentists [26], nursing home nurses [27], etc.). The measurement populations for these scales may be broad or have a finer professional classification [19]. Tools for measuring patient satisfaction also have universal scales (such as those used to measure patient satisfaction in relation to the healthcare service system [28-30], or the satisfaction of hospitalized patients [31]) and specific scales (such as patients' satisfaction with pharmacy staff [32], nurses [33], etc.). The category of measurement tools for patient satisfaction is not as diverse as that of medical staff work satisfaction. An example is the measurement tool of patients' satisfaction with pharmacy staff, which was modified from the measurement tool of patients' satisfaction with healthcare system services [32]. Thus, it can be seen that each satisfaction measurement tool has its design intention for use in accordance with the study objective.

China's "New Medical Reform", which began in 2009, is currently ongoing. The satisfaction of all parties regarding healthcare reform can directly reflect the implementation and effect of various measures for medical reform. Investigation tools for medical staff work satisfaction and patient satisfaction have not been combined with China's new healthcare reforms, as the questionnaire items are not focused on investigating satisfaction with healthcare reform policies and cannot be used to directly investigate satisfaction following the healthcare reform. Research tools will often use foreign measurement scales or scales that were developed before 2009. The five reform priorities of the new healthcare reform are as follows: first, to speed up the construction of the basic medical security system, achieve full coverage and gradually raise the level of funding and security; second, to establish a national basic drug system so that the masses can use drugs safely and effectively; third, it is necessary to improve the basic public health service system, achieve full coverage of the network, change the operational mechanism, and improve the service quality; fourth, to promote the equalization of basic public health services, improve the system and the funding guarantee system, and reduce the basic public health services for urban and rural residents; fifth, to promote a pilot reform of public hospitals, strengthen hospital management, optimize service processes, standardize the diagnosis and treatment activities, improve the level of medical services, and facilitate the public in seeking medical treatment. Therefore, there is a need to develop a scale that is focused on patient satisfaction and medical staff 
work satisfaction following the healthcare reform. A survey on satisfaction with the new healthcare reform was previously carried out in Guangzhou in December 2014 [34,35] and thereafter promoted in different regions in China. Measurement tools that were verified to be effective through preliminary testing in Guangzhou included, medical staff work satisfaction scales, and patient satisfaction scales comprised the tools used in this study. The survey developed for the present study can closely reflect the current status of patient and medical staff satisfaction after healthcare reform, and can subsequently be used to inspect the implementation status and outcomes of various measures in healthcare reform and propose corresponding policy recommendations.

Previous studies have mostly focused on asking study subjects to describe their level of satisfaction (either medical staff or patients) and thus have segregated medical staff and patients, who should, in fact, be a unified whole and mutually provide feedback and respond to healthcare system operations. This study appropriately expands the research horizons to investigate the status of medical staff work satisfaction and patient satisfaction following China's healthcare reform in Wuhan (one of the largest cities in China, with abundant healthcare resources) and viewed doctors and patients as a whole in conducting the research.

\section{Materials and Methods}

\subsection{Study Sample}

The subjects of this study comprised medical staff and patients in public general hospitals and community healthcare service centers/stations (medical institutions that are implementing new health reform policies) in Wuhan City, China. The inclusion criteria for medical staff were: 1. specialists, general practitioners, nurses, medical technicians (pharmacists, radiologists, and medical technologists), public health physicians, and hospital management; 2 . who have worked at the medical institution for more than half a year; 3 . who signed the informed consent form for this study. Exclusion criteria: Medical staff that were in their probation period. Patient inclusion criteria: 1. Patients aged $\geq 18$ years and their relatives; 2 . Patients who had attended for diagnosis and treatment in the given medical institution in the past one year (or this round of diagnosis and treatment has already ended); 3. Inpatient and outpatients were both allowed to participate. Exclusion criteria: 1. Non-patient (e.g., scalpers, migrants); 2. Patients who have just arrived at the hospital and have lost touch with the medical staff access to any diagnosis and treatment.

Based on the level of economic development in the administrative region and hospitals that meet a certain scale (integrated public hospitals that can survey at least 65 patients and 65 medical staff and community healthcare service centers/stations that can investigate at least 20 patients and 20 medical personnel), we randomly selected four pilot district-level/municipal-level integrated public hospitals (three tertiary hospitals and one secondary hospital) and 10 community healthcare service centers/stations (10 primary hospitals). At this stage, the data collected were mainly used to evaluate patient satisfaction and medical staff work satisfaction in 2016 in Wuhan City following the implementation of the healthcare reforms. This study adopted stratified sampling to ensure maximal consideration of sampling representation. A total of 720 questionnaires were distributed to medical staff and 680 questionnaires to patients, for a total of 1400 questionnaires. A total of 696 medical staff questionnaires and 668 patient questionnaires were deemed valid for analysis. Twenty-four medical staff questionnaires and 12 patient questionnaires were ultimately deemed invalid. Missing responses were those with blank space or vague to see. Response rate: $96.67 \%$ for medical staff and $98.23 \%$ for patients. Participants were given a small incentive (a piece of soap or a towel per responder) valued at $5 \mathrm{RMB}$ as compensation for their time. Based on our calculation, the sampling error for medical staff and patient is $3.6 \%$ and $3.8 \%$, respectively.

Trained and qualified investigators conducted this study and distributed unified questionnaires. Self-completion methods were mainly used for the collection of questionnaire data in both the medical staff and patient questionnaires. Once informed consent had been obtained from participants, 
the investigator distributed a questionnaire to them for completion by themselves. Upon completion, the questionnaires were collected and examined for missing items. Throughout the entire study process, the study subjects could ask the investigators if they had any questions or doubts.

To ensure the successful implementation of this study and research quality, rigorous quality control measures were implemented at every stage of the study. A series of measures was used to ensure that differences between the data obtained in this study and the actual situation were kept to a minimum. Quality control was implemented throughout the entire study process: 1 . Sampling stage: Comprehensive consideration of sample representativeness and operable design of the sampling protocol, and strict implementation of sampling according to the sampling protocol. 2. Uniform training of investigators and ensuring that the investigators accurately understood the scale dimensions and items. Investigators had to be clear on their roles and responsibilities and have uniform accurate understanding of the questions in the scale and method of answering enquiry questions (non-guided). Medical staff was provided with assistance as needed, including explanation of the meaning of items or skip patterns. 3. Strict implementation of inclusion and exclusion criteria. 4. Establishment of a verification system for survey quality: The investigator must carry out a complete inspection of the content completed by the subject (patient) on site. Investigators would remind the participants that they might forget several items. If the participants suggested they did not wish to answer, then the investigators would respect their decision. 5 . To ensure the quality of data entry, a dual entry system was used during the data entry stage, which comprised each questionnaire being independently entered by two investigators. After the data had been verified to ensure no missing items or errors, they were used for statistical analysis. 6. Management of missing values: If missing items were found in some questionnaires during the second review, imputation is necessary. The management method (after discussion with experts) was as follows: If the number of missing values in one questionnaire was $>4$, the questionnaire was deemed invalid; If the number of missing values in one questionnaire $\leq 3$, such questionnaires were still deemed valid for statistical analysis. Estimates means, standard deviations, covariances, and correlations for different missing value methods: listwise, pairwise, regression, or expectation-maximization (EM). After implementing Little's MCAR test, it was found that medical staff and patient data belonged to missing at random (MAR) and missing completely at random (MCAR), respectively. Thus, EM and regression method were used for completion of medical staff and patient data, respectively.

\subsection{Instrument}

The study tools comprised two parts:

2.2.1. Medical Staff Work Satisfaction Scale after Healthcare Reform and Patient Satisfaction Scale after Healthcare Reform

The medical staff satisfaction scale following healthcare reform (MSSS-HR, hereinafter referred to as MSSS) and patient satisfaction scale following healthcare reform (PSS-HR, hereinafter referred to as PSS) $[34,35]$ were previously created by the research group based on a literature review of local and overseas measurement tools for medical staff work satisfaction and patient satisfaction and their influencing factors. These were combined with an emphasis on the 2016 national in-depth healthcare system reform to determine the scale dimensions and refine the entry pool. The entry pool was then expanded through two core group interviews. Delphi expert consultation was used to screen the entries in order to generate a preliminary version of the scale. Finally, on-site pre-investigation was used for quantitative evaluation of psychological characteristics. A final improvement was implemented based on the evaluation results to obtain the final scales. MSSS and PSS are progressively used to measure medical staff work satisfaction and patient satisfaction, respectively.

The medical staff work satisfaction scales include five dimensions and 43 items. The five dimensions are: the work itself (first dimension), job reward (second dimension), hospital management (third dimension), work conditions and atmosphere (fourth dimension), and practicing environment 
(fifth dimension). Satisfaction from the work itself was used to evaluate the satisfaction status of medical staff towards workload, job autonomy, job stability, job importance, ability utilization, job achievement, and job responsibilities. Job rewards were used to evaluate the satisfaction of medical staff towards material rewards, mental rewards, and reward fairness. Hospital management was used to evaluate the satisfaction status of medical staff towards the organization and management of their medical institution, including hospital leadership ability, process management in the hospital, system management, current development status, industry status and developmental outlook, etc. Work conditions and atmosphere were derived from the internal working environment of medical staff and used to evaluate the satisfaction status of medical staff towards the facilities and equipment, informatization level, logistical support, interpersonal relationships and collaborative atmosphere, etc. Practicing environment was derived from the external environment of practice by medical staff and evaluates the satisfaction level of medical staff in relation to physician-patient relationship, communication, societal opinion, health policies, etc. In addition, a special item, with 0 to 100 points description, was included at the end of the medical staff work satisfaction questionnaires to evaluate the macro-level work satisfaction of the study subject in the past year (hereinafter referred to as Special Item-MSSS).

The patient satisfaction scales include five dimensions and 29 items. The five dimensions were: physician-patient relationship and communication (first dimension), access to relevant information and support (second dimension), healthcare and related services (third dimension), continuity and collaboration of medical care (fourth dimension), and service organization and facilities (fifth dimension).The physician-patient relationship and communication dimension mainly refer to the level of satisfaction of the patient towards two-way communication during the consultation process. The physician-patient relationship refers to the social interaction process of mutual communication and interaction between physicians and patients. This is a unique interpersonal relationship, with healthcare at its core and maintenance of patient health as its objective. The access to relevant information and support dimension refers to the process by which patients obtain relevant information in relation to medical services and medical insurance from medical staff. The healthcare and related service dimension refers to the services of examination, diagnosis, treatment, recuperation, and preventive healthcare provided by the medical institution to the patients, as well as the drugs, medical equipment, ambulances, and hospital wards that are related to those services. The continuity and collaboration of the medical care dimension refers to the process, design, and implementation of connecting patients to hospital services in order to provide continuous medical services and coordination between medical staff, in order to ensure that the patient's medical information is transferred when the patient is transferred, to ensure continuous medical services when patients are transferred to another department or hospital, or following discharge. The service organization and facilities dimension refers to access to medical care and evaluation of perception towards environment and facilities. In addition, a special item, with 0 to 100 points description, was included at the end of the patient satisfaction questionnaire to evaluate the macro-level patient satisfaction towards medical services in the previous year (hereinafter referred to as Special Item-PSS).

The Likert 5-point evaluation method was used for the response scale of each item, with 1 = extremely dissatisfied, 2 = dissatisfied, 3 = generally satisfied or not, $4=$ satisfied, and $5=$ extremely satisfied, respectively. Another option 6 was also included, which indicated that the respondent "does not understand" the situation; this was converted into an initial value during statistical analysis. The Likert 5-point scale was converted to 0-100 points. Namely, The five-point value range of the standard satisfaction scale was then converted to $0-100$ using the following equation [36]:

$$
\operatorname{adj} S=\frac{100(\operatorname{std} S S-1)}{5-1}
$$

where, "adjSS" and "stdSS" represent the "adjusted satisfaction score" and "standard satisfaction score" respectively. 
Using a new scoring method, the satisfaction evaluation criteria were developed (adjSS shows the final score of the evaluation system and represents the adjusted satisfaction score): "extremely dissatisfied" (adjSS: 0-), "dissatisfied" (20-), "generally satisfied or not" (40-), "satisfied" (60-), and "extremely satisfied" (80-100).

\subsubsection{Self-Designed General Information Questionnaire}

The content of the medical staff work satisfaction includes the class of medical institution, gender, age, practice period, educational level, job title, nature of job, employment status, whether at resident/general physician training stage, etc., in the form of multiple choice questions.

The content of the patient questionnaire includes the class of medical institution, the gender, age, household registration status, employment status, educational level, average monthly family income, medical insurance type, whether or not they purchased commercial insurance, consultation type, consultation department, and self-perceived disease severity of the patients or relatives, in the form of multiple-choice questions.

\subsection{Statistical Analysis}

Microsoft Excel (version 2010, Microsoft, Seattle, WA, USA) and EpiData (version 3.1, Lauritsen JM \& Bruus M, Odense, Denmark) were used to create a database for data entry. IBM SPSS Statistics (version 18.0, SPSS Inc., Chicago, IL, USA) was used for analysis. Statistical analysis included descriptive analysis, Pearson correlation coefficient, t-test, F-test, multiple linear regression, etc. (the data all conformed to the conditions for statistical testing, such as normality testing). Outcome (dependent) variable is actually only the macro-level work satisfaction for the medical staff (The Special Item-MSSS scoring) and the macro-level patient satisfaction towards medical services for the patient (the Special Item-PSS scoring). Before carrying out multiple linear regression analysis, dummy variable quantitation was carried out on independent variables or predictor variables (medical staff general information, patient general information) to avoid collinearity of independent variables. The tests were all two-tailed tests and $p<0.05$ or 0.01 were deemed statistically significant.

\subsection{Ethics Statement}

Before implementing the study, the ethics committee of Wuhan University School of Medicine (WUSM) reviewed it and found it to comply with the Declaration of Helsinki and its revised versions, as well as the relevant regulations of biomedical journals, and approved the research.At the same time, approval was sought from the relevant management departments of the study units and from medical staff and patients. All study subjects signed an informed consent form. Please see the uploaded annex for the ethics approval form.

\section{Results}

The Cronbach's alpha of the medical staff work satisfaction scale was 0.973 and the Cronbach's alpha of each dimension (work itself, job reward, hospital management, work conditions and atmosphere, and practicing environment) were 0.880, 0.860, 0.921, 0.892, and 0.963, respectively. The Cronbach's alpha of the patient satisfaction scale was 0.949 and the Cronbach's alpha of each dimension (physician-patient relationship and communication, access to relevant information and support, healthcare and related services, continuity and collaboration of medical care, and service organization and facilities) were $0.871,0.843,0.888,0.641$, and 0.878 , respectively. The overall reliability of the two scales is thus excellent. Besides continuity and collaboration of medical care (as a dimension, reliability is acceptable), the various dimensions and entire scale all showed ideal and extremely ideal quantitative psychometric characteristics $[37,38]$. Our study indicates that the correlation coefficients of the dimensions of the medical staff work satisfaction scale after healthcare reform (MSSS) and of the entire scale were $0.775,0.864,0.921,0.884$, and 0.888 , respectively; the correlation coefficients of the various dimensions and entire scale of patient satisfaction scale after the healthcare reform (PSS) were 
$0.699,0.828,0.917,0.826$, and 0.881 , respectively. Research in Guangzhou shows that concerning the MSSS, the Spearman correlation coefficient for each item and its own dimension was between 0.70 and 0.92. Most correlation coefficients between items and their hypothesized subscales were higher than those with other subscales. Five factors emerged from the scale. The cumulative variance contribution rate was $71.04 \%$ [34]; as regards the PSS, the scale was composed of 5 dimensions, which could explain $88.223 \%$ of overall variance of the scale. The correlation coefficients between the domain scores and the total score of the scale ranged from 0.881 to 0.937 [35]. The validity of the medical staff work satisfaction scale and patient satisfaction scale in Wuhan after healthcare reform were generally consistent with the pre-investigation in Guangzhou. Table 1 shows the general situation. The measurement results of this survey were stable and the measurement tools have good validity and reliability.

Table 1. Comparison of Cronbach's alpha of the MSSS and PSS between Wuhan and Guangzhou.

\begin{tabular}{ccccc}
\hline & \multicolumn{2}{c}{ MSSS } & \multicolumn{2}{c}{ PSS } \\
\cline { 2 - 5 } & Wuhan & Guangzhou & Wuhan & Guangzhou \\
\hline Scale & 0.973 & 0.98 & 0.949 & 0.98 \\
Dimension1 & 0.880 & 0.90 & 0.871 & 0.93 \\
Dimension2 & 0.860 & 0.89 & 0.843 & 0.88 \\
Dimension3 & 0.921 & 0.92 & 0.888 & 0.86 \\
Dimension4 & 0.892 & 0.89 & 0.641 & 0.86 \\
Dimension5 & 0.963 & 0.95 & 0.878 & 0.83 \\
\hline
\end{tabular}

\subsection{Medical Staff and Patient Satisfaction Status}

Medical staff satisfaction ranking, in sequence from most to least satisfied was: work itself, work environment and atmosphere, hospital management, practicing environment, and job rewards. Among samples of medical staff, the highest point is 100.00 and the lowest point is 10.47 . The correlation coefficient $r$ of overall work satisfaction and the scoring to evaluate the macro-level work satisfaction in the past one year by a special item (the Special Item-MSSS scoring) was $0.605(p<0.001)$. The Special Item-MSSS scoring scored $81.45 \pm 13.24$ and was evaluated as extremely satisfactory.

Patient satisfaction ranking, in sequence from most to least satisfied was: physician-patient relationship and communication, service organization and facilities, continuity and collaboration of medical care, access to relevant information and support, and healthcare and related services. Among samples of patients, the highest point is 100.00 and the lowest point is 8.62. The correlation coefficient $r$ of overall patient satisfaction and the scoring to evaluate the macro-level patient satisfaction towards medical services in the past 1 year by a special item (the Special Item-PSS scoring) was $0.643(p<0.001)$. The Special Item-PSS scoring has scored $81.18 \pm 13.02$ and was evaluated as extremely satisfactory. Medical staff and patient overall satisfaction were evaluated as average and satisfied, respectively. Tables 2 and 3 show the medical staff and patient satisfaction status.

Table 2. Medical staff satisfaction and evaluation.

\begin{tabular}{ccccc}
\hline Dimension & $\begin{array}{c}\text { No. of Items } \\
\text { in Dimension }\end{array}$ & $\begin{array}{c}\text { Adjusted } \\
\text { Satisfaction Score }\end{array}$ & $\begin{array}{c}\text { Satisfaction } \\
\text { Evaluation }\end{array}$ & Ranking \\
\hline Overall work satisfaction & 43 & $58.28 \pm 14.60$ & Average & - \\
Work itself & 8 & $63.03 \pm 13.96$ & Satisfactory & 1 \\
Job rewards & 7 & $54.06 \pm 16.35$ & Average & 5 \\
Hospital management & 8 & $58.53 \pm 17.38$ & Average & 3 \\
Work environment and atmosphere & 8 & $62.97 \pm 15.35$ & Satisfactory & 2 \\
Practicing environment & 12 & $54.28 \pm 19.31$ & Average & 4 \\
\hline
\end{tabular}

Note: Ranked from highest to lowest. 
Table 3. Patient satisfaction and evaluation.

\begin{tabular}{ccccc}
\hline Dimension & $\begin{array}{c}\text { No. of Items } \\
\text { in Dimension }\end{array}$ & $\begin{array}{c}\text { Adjusted } \\
\text { Satisfaction Score }\end{array}$ & $\begin{array}{c}\text { Satisfaction } \\
\text { Evaluation }\end{array}$ & Ranking \\
\hline $\begin{array}{c}\text { Overall patient satisfaction } \\
\text { Physician-patient relationship and }\end{array}$ & 29 & $65.82 \pm 14.66$ & Satisfactory & - \\
communication & 3 & $77.07 \pm 17.44$ & Satisfactory & 1 \\
Access to relevant information and support & 5 & $64.66 \pm 18.46$ & Satisfactory & 4 \\
Healthcare and related services & 9 & $60.88 \pm 17.29$ & Satisfactory & 5 \\
Continuity and collaboration of medical care & 3 & $66.40 \pm 17.21$ & Satisfactory & 3 \\
Service organization and facilities & 9 & $67.47 \pm 16.00$ & Satisfactory & 2 \\
\hline
\end{tabular}

Note: Ranked from highest to lowest.

\subsection{General Demographic Characteristics and Satisfaction Status of Medical Staff and Patients}

Differences were found in the overall satisfaction levels of medical staff in terms of gender, age, educational level, job title, nature of the job, employment status, and whether staff are at the standardized training stage $(p<0.05$ or 0.01$)$. The class of medical institution approached statistical significance $(0.1>p>0.05)$. (Table 4$)$. There was no statistically significant difference in various demographic variables in overall patient satisfaction $(p>0.05)$. Household registration status, type of medical insurance, and consultation type approached statistical significance $(0.1>p>0.05)$. (Table 5).

Table 4. Demographic characteristics associated with the medical staff's job satisfaction $(N=696)$.

\begin{tabular}{|c|c|c|c|c|}
\hline & & $n(\%)$ & $\operatorname{adjSS}$ & $p$ \\
\hline \multirow{2}{*}{$\begin{array}{l}\text { Type of medical } \\
\text { institution (Class) }\end{array}$} & $\begin{array}{l}\text { District/municipal public hospital } \\
\text { (tertiary and secondary) }\end{array}$ & $453(65.1)$ & $58.96 \pm 14.94$ & \multirow[t]{2}{*}{0.092} \\
\hline & $\begin{array}{l}\text { Community healthcare service } \\
\text { center/stations (Primary hospitals) }\end{array}$ & $243(34.9)$ & $57.00 \pm 13.87$ & \\
\hline \multirow[b]{2}{*}{ Gender } & Male & $181(26.0)$ & $55.76 \pm 15.87$ & \multirow{2}{*}{$0.007^{* *}$} \\
\hline & Female & $515(74.0)$ & $59.16 \pm 14.03$ & \\
\hline \multirow{5}{*}{ Age } & $18-29$ & $290(41.7)$ & $59.96 \pm 14.59$ & \multirow{5}{*}{$0.049 *$} \\
\hline & 30-39 & $245(35.2)$ & $57.26 \pm 15.08$ & \\
\hline & $40-49$ & $101(14.5)$ & $55.62 \pm 14.32$ & \\
\hline & $50-59$ & $52(7.5)$ & $58.04 \pm 12.46$ & \\
\hline & $>60$ years & $8(1.1)$ & $63.74 \pm 9.28$ & \\
\hline \multirow{5}{*}{ Practicing period } & $<5$ years & $271(38.9)$ & $59.12 \pm 14.37$ & \multirow{5}{*}{0.590} \\
\hline & $6-10$ years & $166(23.9)$ & $58.21 \pm 15.66$ & \\
\hline & $11-15$ years & $97(13.9)$ & $58.67 \pm 15.27$ & \\
\hline & 16-20 years & $42(6.0)$ & $56.60 \pm 14.06$ & \\
\hline & Over 20 years & $120(17.2)$ & $56.76 \pm 13.23$ & \\
\hline \multirow{4}{*}{ Educational level } & $\begin{array}{l}\text { High school, vocational school, } \\
\text { polytechnic and below }\end{array}$ & $28(4.0)$ & $59.69 \pm 12.89$ & \multirow{4}{*}{$0.015 *$} \\
\hline & College or senior technical school & $140(20.1)$ & $58.94 \pm 13.08$ & \\
\hline & Undergraduate & $372(53.4)$ & $59.32 \pm 14.85$ & \\
\hline & Graduate student and above & $156(22.4)$ & $54.96 \pm 15.19$ & \\
\hline \multirow{5}{*}{ Job title } & None & $63(9.1)$ & $61.19 \pm 16.67$ & \multirow{5}{*}{$0.003 * *$} \\
\hline & Junior & $367(52.7)$ & $59.75 \pm 13.84$ & \\
\hline & Intermediate & $202(29.0)$ & $55.20 \pm 14.52$ & \\
\hline & Vice-senior & $55(7.9)$ & $56.93 \pm 14.96$ & \\
\hline & Senior & $9(1.3)$ & $55.06 \pm 18.76$ & \\
\hline \multirow{6}{*}{ Nature of job } & Specialist & $177(25.4)$ & $53.67 \pm 14.85$ & \multirow{6}{*}{$<0.001^{* *}$} \\
\hline & General practitioner & $41(5.9)$ & $54.18 \pm 15.00$ & \\
\hline & $\begin{array}{l}\text { Medical technical staff (pharmacist, } \\
\text { medical technologist, radiologist, etc.) }\end{array}$ & $42(6.0)$ & $63.06 \pm 13.65$ & \\
\hline & Nurse & $342(49.1)$ & $60.86 \pm 14.33$ & \\
\hline & Public health physician & $56(8.0)$ & $54.04 \pm 12.64$ & \\
\hline & Management staff & $38(5.5)$ & $61.94 \pm 11.23$ & \\
\hline
\end{tabular}


Table 4. Cont.

\begin{tabular}{ccccc}
\hline & & $\boldsymbol{n}(\mathbf{\%})$ & adjSS & $p$ \\
\hline \multirow{2}{*}{ Employment status } & In-house staff & $210(30.2)$ & $56.26 \pm 15.15$ & \\
& $\begin{array}{c}\text { Contract staff } \\
\end{array}$ & $324(46.6)$ & $60.28 \pm 13.76$ & $0.003 * *$ \\
& $\begin{array}{c}\text { Others (labor dispatch, personnel } \\
\text { agency, secondment, retiree, etc.) }\end{array}$ & $162(23.3)$ & $56.90 \pm 15.06$ & \\
\hline $\begin{array}{c}\text { Whether at resident/general } \\
\text { physician training stage }\end{array}$ & Yes & $114(16.4)$ & $62.28 \pm 15.33$ & \multirow{2}{*}{$0.0011^{* *}$} \\
\hline
\end{tabular}

Note: ${ }^{*} p<0.05,{ }^{* *} p<0.01$.

Table 5. Demographic characteristics associated with the patients' satisfaction $(N=668)$.

\begin{tabular}{|c|c|c|c|c|}
\hline & & $n(\%)$ & adjSS & $p$ \\
\hline \multirow[t]{2}{*}{ Type of medical institution (Class) } & $\begin{array}{l}\text { District/municipal public hospital } \\
\text { (secondary and tertiary) }\end{array}$ & $401(60.0)$ & $65.74 \pm 15.03$ & \multirow[t]{2}{*}{0.863} \\
\hline & $\begin{array}{c}\text { Community healthcare service } \\
\text { center/stations (Class 1) }\end{array}$ & $267(40.0)$ & $65.94 \pm 14.12$ & \\
\hline \multirow{2}{*}{ Gender } & Male & $289(43.3)$ & $66.69 \pm 14.74$ & \multirow{2}{*}{0.180} \\
\hline & Female & $379(56.7)$ & $65.16 \pm 14.59$ & \\
\hline \multirow{5}{*}{ Age } & $18-29$ years & $191(28.6)$ & $66.06 \pm 14.79$ & \multirow{5}{*}{0.493} \\
\hline & 30-39 years & $111(16.6)$ & $63.95 \pm 12.19$ & \\
\hline & $40-49$ years & $88(13.2)$ & $65.89 \pm 14.82$ & \\
\hline & $50-59$ years & $116(17.4)$ & $67.50 \pm 15.84$ & \\
\hline & $>60$ years & $162(24.3)$ & $65.59 \pm 15.12$ & \\
\hline \multirow{4}{*}{ Household registration status } & Local urban resident & $346(51.8)$ & $65.28 \pm 14.48$ & \multirow{4}{*}{0.074} \\
\hline & Local agricultural worker & $65(9.7)$ & $62.52 \pm 15.10$ & \\
\hline & Foreign permanent resident & $117(17.5)$ & $67.88 \pm 15.01$ & \\
\hline & Foreign non-permanent resident & $140(21.0)$ & $66.98 \pm 14.39$ & \\
\hline \multirow{8}{*}{ Employment status } & Government agencies & $28(4.2)$ & $66.44 \pm 17.00$ & \multirow{8}{*}{0.181} \\
\hline & Enterprises and institutions & $155(23.2)$ & $65.19 \pm 15.69$ & \\
\hline & Freelancer & $131(19.6)$ & $66.05 \pm 14.06$ & \\
\hline & Foreign laborer & $41(6.1)$ & $66.57 \pm 13.01$ & \\
\hline & Unemployed & $35(5.2)$ & $64.54 \pm 15.65$ & \\
\hline & Student & $49(7.3)$ & $71.78 \pm 13.28$ & \\
\hline & Retiree & $177(26.5)$ & $64.58 \pm 14.41$ & \\
\hline & Others & $52(7.8)$ & $65.68 \pm 13.78$ & \\
\hline \multirow{6}{*}{ Educational level } & Primary school and below & $40(6.0)$ & $68.83 \pm 12.72$ & \multirow{6}{*}{0.209} \\
\hline & Junior high school & 133 (19.9) & $67.14 \pm 12.25$ & \\
\hline & Vocational school & $71(10.6)$ & $65.63 \pm 14.72$ & \\
\hline & High school, polytechnic & $115(17.2)$ & $66.84 \pm 13.56$ & \\
\hline & College & $128(19.2)$ & $63.34 \pm 17.23$ & \\
\hline & Undergraduate and above & $181(27.1)$ & $65.37 \pm 15.26$ & \\
\hline \multirow{5}{*}{$\begin{array}{l}\text { Average household monthly } \\
\text { income (RMB) }\end{array}$} & $0 \sim$ & $22(3.3)$ & $59.46 \pm 16.60$ & \multirow{5}{*}{0.225} \\
\hline & $500 \sim$ & $121(18.1)$ & $66.32 \pm 12.38$ & \\
\hline & $2000 \sim$ & $271(40.6)$ & $65.59 \pm 14.29$ & \\
\hline & $4000 \sim$ & $184(27.5)$ & $65.82 \pm 16.54$ & \\
\hline & $8000 \sim$ & $70(10.5)$ & $67.84 \pm 13.63$ & \\
\hline \multirow{5}{*}{$\begin{array}{l}\text { Average household monthly } \\
\text { income (RMB) }\end{array}$} & UEBMI & $283(42.4)$ & $64.81 \pm 14.15$ & \multirow{5}{*}{0.064} \\
\hline & URBMI & $145(21.7)$ & $67.27 \pm 15.18$ & \\
\hline & NCMS & $158(23.7)$ & $64.63 \pm 13.49$ & \\
\hline & Others & $48(7.2)$ & $67.61 \pm 16.51$ & \\
\hline & None (self-paid) & $34(5.1)$ & $71.08 \pm 17.82$ & \\
\hline \multirow{2}{*}{ Purchased commercial insurance } & Yes & $145(21.7)$ & $65.35 \pm 15.26$ & \multirow{2}{*}{0.664} \\
\hline & No & $523(78.3)$ & $65.95 \pm 14.51$ & \\
\hline \multirow{2}{*}{ Consultation type } & Outpatient & $362(54.2)$ & $64.89 \pm 14.36$ & \multirow{2}{*}{0.074} \\
\hline & Inpatient & $306(45.8)$ & $66.92 \pm 14.96$ & \\
\hline \multirow{5}{*}{ Consultation department } & Internal medicine & $301(45.1)$ & $66.78 \pm 14.56$ & \multirow{5}{*}{0.204} \\
\hline & Surgery & $135(20.2)$ & $66.72 \pm 14.99$ & \\
\hline & Gynecology & $61(9.1)$ & $65.42 \pm 17.23$ & \\
\hline & Pediatrics & $17(2.5)$ & $63.44 \pm 9.43$ & \\
\hline & Others & $154(23.1)$ & $63.57 \pm 13.82$ & \\
\hline
\end{tabular}


Table 5. Cont.

\begin{tabular}{lcccc}
\hline & & $n \mathbf{( \% )}$ & adjSS & $p$ \\
\hline \multirow{3}{*}{ Self-perceived disease severity } & Slight & $169(25.3)$ & $65.93 \pm 14.04$ & \\
& Moderate & $317(47.5)$ & $65.17 \pm 14.41$ & 0.461 \\
& Serious & $182(27.2)$ & $66.86 \pm 15.66$ & \\
\hline
\end{tabular}

Note: UEBMI: Urban Employee Basic Medical Insurance; URBMI: Urban Resident Basic Medical Insurance; NCMS: New Cooperative Medical System.

\subsection{Multiple Linear Regression Analysis}

In Table 6, the macro-level work satisfaction for the medical staff (The scoring Special Item-MSSS) was a dependent variable, while the five dimensions in the medical staff work satisfaction scale and demographic characteristics were independent variables (after the addition of dummy variables). The results of multiple linear regression were that hospital management, practicing environment, work itself, regular training, age, nature of job, and employment status showed statistical significance ( $p<0.05$ or 0.01 ), can be included in the regression formula, and explain $39.3 \%$ of the variance.

In Table 7, the macro-level patient satisfaction towards medical services for the patient (The scoring Special Item-PSS) was a dependent variable and the five dimensions in the patient satisfaction scale and demographic characteristics were independent variables (after the addition of dummy variables).

Table 6. Results of multi-factor linear regression analysis for the medical staff's job satisfaction.

\begin{tabular}{|c|c|c|c|c|c|}
\hline Relative Factors & $\begin{array}{l}\text { Partial Regression } \\
\text { Coefficients }\end{array}$ & Standard Error & $\begin{array}{c}\text { Standardized Partial } \\
\text { Regression Coefficients }\end{array}$ & $\mathrm{T}$ & $p$ \\
\hline Constant & 62.072 & & & & \\
\hline Hospital management & 0.196 & 0.039 & 0.257 & 4.962 & $<0.001$ \\
\hline Practicing Environment & 0.176 & 0.032 & 0.256 & 5.443 & $<0.001$ \\
\hline Work itself & 0.154 & 0.040 & 0.162 & 3.844 & $<0.001$ \\
\hline $\begin{array}{c}\text { Regular training } \\
\text { (Yes, Reference: None) }\end{array}$ & -2.688 & 1.191 & -0.075 & -2.256 & 0.024 \\
\hline Age $(18-29$, reference $>60)$ & -10.276 & 4.977 & -0.383 & -2.065 & 0.039 \\
\hline Age $(30-39$, reference $>60)$ & -10.210 & 4.787 & -0.368 & -2.133 & 0.033 \\
\hline $\begin{array}{l}\text { Nature of job (medical } \\
\text { technician, reference: } \\
\text { management) }\end{array}$ & -4.832 & 2.372 & -0.087 & -2.037 & 0.042 \\
\hline $\begin{array}{c}\text { Employment status } \\
\text { (in-house, reference: others) }\end{array}$ & -3.181 & 1.433 & -0.110 & -2.220 & 0.027 \\
\hline
\end{tabular}

Note: $R^{2}=0.415$, adj $R^{2}=0.393(\mathrm{~F}=18.287, p<0.001)$.

Table 7. Results of multi-factor linear regression analysis for the patients' satisfaction.

\begin{tabular}{|c|c|c|c|c|c|}
\hline Relative Factors & $\begin{array}{l}\text { Partial Regression } \\
\text { Coefficients }\end{array}$ & Standard Error & $\begin{array}{c}\text { Standardized Partial } \\
\text { Regression Coefficients }\end{array}$ & $\mathbf{T}$ & $p$ \\
\hline Constant & 45.834 & & & & \\
\hline Service organization and facilities & 0.222 & 0.038 & 0.273 & 5.817 & $<0.001$ \\
\hline $\begin{array}{c}\text { Access to relevant } \\
\text { information and support }\end{array}$ & 0.073 & 0.030 & 0.104 & 2.405 & 0.016 \\
\hline $\begin{array}{l}\text { Educational level (primary school, } \\
\text { reference: undergraduate and above) }\end{array}$ & 4.549 & 2.155 & 0.083 & 2.111 & 0.035 \\
\hline $\begin{array}{l}\text { Average household monthly income } \\
\text { (500-2000 RMB, reference: } 8000-)\end{array}$ & 3.830 & 1.655 & 0.113 & 2.314 & 0.021 \\
\hline $\begin{array}{l}\text { Medical insurance type } \\
\text { (NCMS, reference: None) }\end{array}$ & -4.145 & 2.022 & -0.135 & -2.050 & 0.041 \\
\hline
\end{tabular}


Table 7. Cont.

\begin{tabular}{ccccc}
\hline Relative Factors & $\begin{array}{c}\text { Partial Regression } \\
\text { Coefficients }\end{array}$ & Standard Error & $\begin{array}{c}\text { Standardized Partial } \\
\text { Regression Coefficients }\end{array}$ & T \\
\hline $\begin{array}{c}\text { Self-perceived disease severity } \\
\text { (moderate, reference: serious) }\end{array}$ & 2.330 & 1.007 & 0.089 & 2.315 \\
\hline $\begin{array}{c}\text { Hospital class (secondary and tertiary, } \\
\text { reference: primary hospital) }\end{array}$ & 2.254 & 0.966 & 0.085 & 2.332 \\
\hline
\end{tabular}

Note: $R^{2}=0.455$, adjR ${ }^{2}=0.423(\mathrm{~F}=14.197, p<0.001)$.

The multiple linear regression results found that healthcare and related services, service organization and facilities, access to relevant information and support, educational level, average household monthly income, type of medical insurance, self-perceived disease severity, and hospital class showed statistical significance $(p<0.05$ or 0.01$)$, can be included in the regression formula, and explain $42.3 \%$ of the variance.

\section{Discussion}

\subsection{Medical Staff Satisfaction Status}

The overall work satisfaction for medical staff was average and the scoring to evaluate the macro-level work satisfaction in the past one year by a special item (the Special Item-MSSS scoring) was extremely satisfactory. For work itself and work environment and atmosphere, the satisfaction evaluation results were satisfactory. For job rewards, hospital management, and practicing environment, the satisfaction evaluation results were average. The above conclusion was consistent with survey results from other provinces in China (such as Guangdong, Anhui, Xinjiang, Chongqing, etc.) $[36,39,40]$. Against the background of "new healthcare reforms", medical staff have a higher social status, stronger job achievement, and sufficient ability to perform their job. At the same time, the improved hospital work environment has created a better work atmosphere and stimulated job creativity in medical staff, resulting in greater satisfaction in relation to the work itself and hospital environment. However, in terms of job rewards, some hospitals in China continue to adopt the former personnel allocation system, while salaries were allocated according to years of experience, and this does not adequately reflect the job value of medical staff. This resulted in medical staff feeling that job rewards were not in line with their efforts and did not meet their expectations [41]. Optimization of the reward system and improvement of the salary allocation system: An internal, scientific, and suitable method should be used to determine the contributions and value of staff so that staff will feel that the salary system is reasonable. The establishment of a competitive salary system, and ensuring that salary levels are consistent with external markets, will also give medical staff a feeling of fairness. Currently, international medical institutions have begun to explore new salary allocation models, such as the balanced score card theory, which is a healthcare system using a performance-based salary system [42], as well as the use of a resource-based relative value scale (RBRVS) evaluation system to ensure reasonable payment of physician service fees (remuneration payment method) [43], which are useful as a reference for local hospitals. In terms of hospital organization and management, leadership style has a subtle influence on medical staff satisfaction, and management staff should select the optimal leadership style according to the hospital culture and maturity of the staff in respect to the organization [44]. For the practicing environment, medical staff were not very satisfied and there are many reasons for this: tense physician-patient relationships, external public pressure (sometimes the media were misled and did not fairly report medical malpractice, violence towards doctors, rumors, etc.), changes in health policies (resident/general physician training, multiple licenses), etc., particularly violent incidents in the medical institution, and healthcare disturbance [45], which occurs occasionally. These can result psychological problems in medical staff, which can affect their quality of life [46], cause them to be dissatisfied with the practicing environment, and decrease work satisfaction [47]. In addition, in communication, as the party with greater information, when medical 
staff execute their notification roles, there is a need to be detailed in explaining their job, maintain healthy communications with the patient, and place the patient at the center (through empathy, communication skills, time and information sharing, etc.), in order to alleviate tense physician-patient relationships [48,49]. Macroscopically, medical staff in Wuhan city were satisfied with their work in the last one year and this is largely due to a positive attitude towards work.

In terms of demographic characteristics, this study found that the level of satisfaction was relatively higher in females and this was consistent with a number of previous studies in China [36]. However, other studies have also found that male gender is a positive influencing factor for work satisfaction in medical staff [50], while still others found no differences between male and female medical staff in terms of satisfaction [51,52]. Therefore, further study on the effects of gender on work satisfaction is required. For age, there was a "U-shape distribution" of satisfaction with ages 40-49 years showing the lowest level of satisfaction. This may be because medical staff in this age group may be at their peak of their career and have "professional plateau" reactions, which manifest as significant burnout [53]. Medical staff with educational levels of graduate student and above had the lowest level of satisfaction. This is because highly educated medical staff have higher qualifications and technical expertise, and as a result have more job responsibilities and stress in their departments. Medical staff with no job title or junior medical staff have a higher level of satisfaction, while intermediate and senior medical staff have a lower level of satisfaction. This result is identical to the results of studies in Anhui and Xinjiang provinces [36]. Staff with no job title and junior staff have only recently entered the workforce or have been working for a short period of time. In addition, as they have little work experience, factors such as promotion, treatment, training, and learning will create negative effects on work satisfaction. However, intermediate and senior medical staff are the backbone of medical institutions and have greater work intensity and occupational risks, bear more responsibilities, and face greater burnout and psychological stress. This results in low work satisfaction in this group. In terms of job nature, medical technicians and management staff have higher satisfaction levels compared with physicians and nurses. This is because they have regular rest periods (generally, they start and finish work on time, with little overtime) and have no direct contact with patients, leading to a higher level of satisfaction. Nurses have a higher level of satisfaction than physicians as, under the Chinese healthcare system, physicians are the leaders in diagnosis and treatment, while nurses play a subordinate role in these tasks (physicians have the authority to prescribe drugs but not nurses [54]). Thus, nurses face fewer risks and less stress than physicians. Contract medical staff and medical staff that are undergoing standardized training have a higher level of work satisfaction. This is because they have lower educational levels, experience, or technical expertise, and value their current positions. They also have lower expectations and these results in greater work satisfaction. In addition, the difference in the level of satisfaction between medical staff in different types of medical institution approached statistical significance. Medical staff in secondary and tertiary hospitals (district/municipal public hospitals) have higher levels of satisfaction compared with primary hospitals (community healthcare service center/stations) as higher-class hospitals have a better work environment and conditions.

\subsection{Patient Satisfaction Status}

This study showed that overall patient satisfaction evaluation under the "new healthcare reform" was satisfactory, and that the 5-dimension evaluation was satisfactory. Of the five dimensions, although patients were satisfied with healthcare and related services (barely satisfied), this factor ranked the lowest. The scoring to evaluate the macro-level patient satisfaction towards medical services in the past 1 year by a special item (the Special Item-PSS scoring) was also very satisfactory. This reflects the effectiveness of reform initiatives in the "new healthcare reform" policy towards shortcomings that have been present for a long time in the healthcare domain and has reversed the damage in market orientation towards the healthcare domain. The reforms have resulted in a return to fairness and welfare in basic healthcare services [55], and has secured gratifying progress and breakthroughs and fostered widespread approval and recognition from patients. 
In terms of demographic information, the levels of medical insurance of inpatients and outpatients in Wuhan City was 94.9\%, and this has achieved the goal of the basic medical insurance system, covering $90 \%$ of urban and rural residents. This demonstrates that the national public health insurance scheme has gradually taken shape. In recent years, with the continuous expansion of medical insurance coverage, medical insurance payment levels have increased, and the rapid growth of per capita healthcare costs have been controlled to some extent. Government, social, and individual healthcare expenditure are basically balanced and can reasonably share healthcare costs [56]. In addition, it has been found that the differences in overall satisfaction between patients with different types of medical insurance approached statistical significance: Patients with no medical insurance (self-paid) have the highest level of satisfaction. This may be because the majority of these patients have better financial capabilities or are in a better state of health, have stronger immunity, or less severe symptoms. This was not in line with conventional thinking that patients with medical insurance have a higher level of satisfaction [57]. Some studies found that patients with urban occupational health insurance have a higher level of satisfaction [58]. The greatest challenge faced by China's new healthcare reform is in relation to how medical insurance institutions can implement effective constraints and controls on medical institutions so that the latter can provide cost-effective medical services to insured patients and ultimately ensure universal public health insurance. Differences in household approached statistical significance and foreign populations have a higher level of satisfaction than local populations. This is because the majority of foreign populations were service workers from areas around Wuhan, and healthcare in their hometown may not be as good as the healthcare conditions and environment in Wuhan. In terms of patient type, their differences approached statistical significance as inpatients have a higher level of satisfaction than outpatients. Generally, inpatients undergo outpatient consultation and have a longer contact time with the medical institution and medical staff (outpatients have shorter consultations times and their conditions are often less serious) and can better experience medical services during the treatment process, resulting in increased satisfaction.

\section{Limitations and Suggestions for Future Research}

Although our investigators have carried out in-depth exploration of satisfaction in medical staff and patients and analyzed several factors, we believe that the study has some shortcomings (e.g., Because the research objects are too busy, only fewer emergency medical staff and patients included in this study), with factors that were difficult to estimate excluded from the study (such as living state, marital status, the patient's objective condition, etc.). We hope that in the future, we can include more variables (factors) that affect medical staff work satisfaction and patient satisfaction for a further in-depth study:

1 The study sample only comprised 14 medical institutions in one major city (Wuhan) in China. We did not include other cities in China to obtain a larger sample because different regions have different economic progress and cultural differences, which may affect satisfaction. We can focus on certain sections of the responder satisfaction in future research, like pre-hospital emergency [59].

2 The cross-sectional design of this study limited the inference of causal relationships and was time based. The study tools were only tested in Guangzhou and Wuhan. Although the effectiveness of the tools was initially verified, more samples from different regions and medical institutions are required for continuous measurement and verification in order to optimize and improve the measurement tool.

3 While the data presented in this study were quantitative, at the same time, qualitative descriptive data were also collected from medical staff and patients (through panel discussions, etc.). Due to the limitations on manuscript length, we will carry out more in-depth verification and comparison of qualitative data in the further study. 


\section{Conclusions}

This study has shown that the overall satisfaction of medical staff is affected by many variables, including those found to be statistically significant in the previous sections. However, satisfaction is not only limited to these factors. Although patient satisfaction did not show any statistically significant differences in the demographic data of enrolled patients, some variables still approached statistical significance and deserve further study for verification.

On the whole, the overall satisfaction evaluation of medical staff was average. Healthcare policy makers and the management of medical institutions should focus on the aspects of job rewards and practicing environment in order to decrease the risk of dissatisfaction in medical staff and increase their work happiness and sense of belonging so that they can provide better medical services to patients. The overall patient evaluation was satisfactory and patients were satisfied in all levels of the satisfaction evaluation. However, further improvements and enhancements should be made in healthcare and related services.

Acknowledgments: Project funding: This topic "the satisfaction of the survey after the New Medical Reform" is a part of the sub-topic of the Sun Yat-sen University scientific research project "Healthy China" (Grant No. 99123-18823303). Additionally, the study was supported by the National Natural Science Foundation of China (Grant No. 81773552), the National Natural Science Foundation of China (Grant No. 81273179). We would like to thank the medical staff and patients who volunteered to participate in the investigation of several medical institutions in Wuhan as well as thank the investigators who worked hard to carry out the research program. Moreover, we are grateful to Dr. Shuping Sang (from School of Medicine, Yunnan University) and Associate Professor Junan Liu (from School of Public Health, Tongji Medical College, Huazhong University of Science and Technology) for providing valuable assistance and guidance; all authors appreciated the anonymous reviewers for insightful comments and suggestions to improve the quality of the manuscript.

Author Contributions: Chuanhua Yu, Runtang Meng and Yuantao Hao conceived and designed the project; Runtang Meng collected the data and analyzed the data; Xiaohan Liu, Yanxia Zhao and Yuantao Hao contributed research instruments; Runtang Meng, Jingjing Li, Yunquan Zhang, Yong Yu, Yi Luo and Ying Hu wrote the paper; Runtang Meng and Jingjing Li jointly revised the manuscript. All authors read and approved the final manuscript.

Conflicts of Interest: The authors declare no conflict of interest.

\section{References}

1. Robbins, S.P. Organizational Behavior: International Version, 13/e; Pearson Education India: New Delhi, India, 2009.

2. Vanagas, G.; Bihari-Axelsson, S. The factors associated to psychosocial stress among general practitioners in Lithuania. Cross-sectional study. BMC Health Serv. Res. 2005, 5, 45. [CrossRef] [PubMed]

3. Lu, Y.; Hu, X.-M.; Huang, X.-L.; Zhuang, X.-D.; Guo, P.; Feng, L.-F.; Hu, W.; Chen, L.; Zou, H.; Hao, Y.-T. The relationship between job satisfaction, work stress, work-family conflict, and turnover intention among physicians in Guangdong, China: A cross-sectional study. BMJ Open 2017, 7, e014894. [CrossRef] [PubMed]

4. Holtom, B.C.; O'Neill, B.S. Job embeddedness: A theoretical foundation for developing a comprehensive nurse retention plan. J. Nurs. Admin. 2004, 34, 216-227. [CrossRef]

5. Wang, H.; Tang, C.; Zhao, S.; Meng, Q.; Liu, X. Job satisfaction among health-care staff in township health centers in rural China: Results from a latent class analysis. Int. J. Environ. Res. Public Health 2017, $14,1101$. [CrossRef] [PubMed]

6. Thornton, R.D.; Nurse, N.; Snavely, L.; Hackett-Zahler, S.; Frank, K.; DiTomasso, R.A. Influences on patient satisfaction in healthcare centers: A semi-quantitative study over 5 years. BMC Health Serv. Res. 2017, 17, 361. [CrossRef] [PubMed]

7. Molyneux, J. Nurses' job satisfaction linked to patient satisfaction. AJN Am. J. Nurs. 2011, 111, 16. [CrossRef] [PubMed]

8. Haas, J.S.; Cook, E.F.; Puopolo, A.L.; Burstin, H.R.; Cleary, P.D.; Brennan, T.A. Is the professional satisfaction of general internists associated with patient satisfaction? J. Gen. Intern. Med. 2000, 15, 122-128. [CrossRef] [PubMed] 
9. Palese, A.; Gonella, S.; Fontanive, A.; Guarnier, A.; Barelli, P.; Zambiasi, P.; Allegrini, E.; Bazoli, L.; Casson, P.; Marin, M. The degree of satisfaction of in-hospital medical patients with nursing care and predictors of dissatisfaction: Findings from a secondary analysis. Scand. J. Caring Sci. 2017, 31, 768-778. [CrossRef] [PubMed]

10. Naidu, A. Factors affecting patient satisfaction and healthcare quality. Int. J. Health Care Qual. Assur. 2009, 22, 366-381. [CrossRef] [PubMed]

11. Andaleeb, S.S. Service quality perceptions and patient satisfaction: A study of hospitals in a developing country. Soc. Sci. Med. 2001, 52, 1359-1370. [CrossRef]

12. Aharony, L.; Strasser, S. Patient satisfaction: What we know about and what we still need to explore. Med. Care Rev. 1993, 50, 49-79. [CrossRef] [PubMed]

13. Wong, E.L.; Coulter, A.; Cheung, A.W.; Yam, C.H.; Yeoh, E.-K.; Griffiths, S. Item generation in the development of an inpatient experience questionnaire: A qualitative study. BMC Health Serv. Res. 2013, 13, 265. [CrossRef] [PubMed]

14. Batbaatar, E.; Dorjdagva, J.; Luvsannyam, A.; Savino, M.M.; Amenta, P. Determinants of patient satisfaction: A systematic review. Perspect. Public Health 2017, 137, 89-101. [CrossRef] [PubMed]

15. Ahmad, W.; Krupat, E.; Asma, Y.; Attique, R.; Mahmood, U.; Waqas, A. Attitudes of medical students in Lahore, Pakistan towards the doctor-patient relationship. PeerJ 2015, 3, e1050. [CrossRef] [PubMed]

16. McCabe, C. Nurse-patient communication: An exploration of patients' experiences. J. Clin. Nurs. 2004, 13, 41-49. [CrossRef] [PubMed]

17. Lambrou, P.; Kontodimopoulos, N.; Niakas, D. Motivation and job satisfaction among medical and nursing staff in a cyprus public general hospital. Hum. Resour. Health 2010, 8, 26. [CrossRef] [PubMed]

18. Kane, R.L.; Maciejewski, M.; Finch, M. The relationship of patient satisfaction with care and clinical outcomes. Med. Care 1997, 35, 714-730. [CrossRef] [PubMed]

19. Chang, E.; Cohen, J.; Koethe, B.; Smith, K.; Bir, A. Measuring job satisfaction among healthcare staff in the United States: A confirmatory factor analysis of the satisfaction of employees in health care (SEHC) survey. Int. J. Qual. Health Care 2017, 29, 262-268. [CrossRef] [PubMed]

20. Suhonen, R.; Leino-Kilpi, H.; Välimäki, M.; Kim, H.S. The patient satisfaction scale-An empirical investigation into the Finnish adaptation. J. Eval. Clin. Pract. 2007, 13, 31-38. [CrossRef] [PubMed]

21. Spector, P.E. Measurement of human service staff satisfaction: Development of the job satisfaction survey. Am. J. Community Psychol. 1985, 13, 693-713. [CrossRef] [PubMed]

22. Alpern, R.; Canavan, M.E.; Thompson, J.T.; McNatt, Z.; Tatek, D.; Lindfield, T.; Bradley, E.H. Development of a brief instrument for assessing healthcare employee satisfaction in a low-income setting. PLoS ONE 2013, 8, e79053. [CrossRef] [PubMed]

23. Lichtenstein, R. Measuring the job satisfaction of physicians in organized settings. Med. Care 1984, 56-68. [CrossRef]

24. Lloyd, S.; Streiner, D.; Hahn, E.; Shannon, S. Development of the emergency physician job satisfaction measurement instrument. Am. J. Emerg. Med. 1994, 12,1-10. [CrossRef]

25. Traynor, M.; Wade, B. The development of a measure of job satisfaction for use in monitoring the morale of community nurses in four trusts. J. Adv. Nurs. 1993, 18, 127-136. [CrossRef] [PubMed]

26. Cui, X.; Dunning, D.G.; An, N. Satisfaction among early and mid-career dentists in a metropolitan dental hospital in China. J. Healthc. Leadersh. 2017, 9, 35. [CrossRef] [PubMed]

27. Castle, N.G. Assessing job satisfaction of nurse aides in nursing homes: The nursing home nurse aide job satisfaction questionnaire. J. Gerontol. Nurs. 2007, 33, 41-47. [PubMed]

28. Larsen, D.L.; Attkisson, C.C.; Hargreaves, W.A.; Nguyen, T.D. Assessment of client/patient satisfaction: Development of a general scale. Eval. Program Plan. 1979, 2, 197-207. [CrossRef]

29. Nguyen, T.D.; Attkisson, C.C.; Stegner, B.L. Assessment of patient satisfaction: Development and refinement of a service evaluation questionnaire. Eval. Program Plan. 1983, 6, 299-313. [CrossRef]

30. Ware, J.E., Jr.; Snyder, M.K.; Wright, W.R.; Davies, A.R. Defining and measuring patient satisfaction with medical care. Eval. Program Plan. 1983, 6, 247-263. [CrossRef]

31. González, N.; Quintana, J.M.; Bilbao, A.; Escobar, A.; Aizpuru, F.; Thompson, A.; Esteban, C.; Sebastián, J.A.S.; De La Sierra, E. Development and validation of an in-patient satisfaction questionnaire. Int. J. Qual. Health Care 2005, 17, 465-472. [CrossRef] [PubMed] 
32. MacKeigan, L.D.; Larson, L.N. Development and validation of an instrument to measure patient satisfaction with pharmacy services. Med. Care 1989, 522-536. [CrossRef]

33. La Monica, E.L.; Oberst, M.T.; Madea, A.R.; Wolf, R.M. Development of a patient satisfaction scale. Res. Nurs. Health 1986, 9, 43-50. [CrossRef] [PubMed]

34. Zhao, Y.-X.; Liu, X.-H.; Shao, Z.-J.; Hu, R.-W.; Hao, Y.-T. Design of job satisfaction scale for medical staff. Mod. Prev. Med. 2016, 43, 3190-3199.

35. Liu, X.-H.; Zhao, Y.-X.; Hu, R.-W.; Shao, Z.-J.; Hao, Y.-T. Development, reliability and validity evaluation of a satisfaction scale for patients after healthcare reform. Chin. J. Public Health 2017, 33, 145-148.

36. Liu, J.A.; Wang, Q.; Lu, Z.X. Job satisfaction and its modeling among township health center employees: A quantitative study in poor rural china. BMC Health Serv. Res. 2010, 10, 115. [CrossRef] [PubMed]

37. Krabbe, P. The Measurement of Health and Health Status: Concepts, Methods and Applications from a Multidisciplinary Perspective; Academic Press: Waltham, MA, USA, 2016.

38. Wu, M.-L. Statistical Analysis of the Questionnaire: SPSS Operation and Application; Chongqing University Press: Chongqing, China, 2010.

39. Lu, Y.; Hu, X.-M.; Huang, X.-L.; Zhuang, X.-D.; Guo, P.; Feng, L.-F.; Hu, W.; Chen, L.; Hao, Y.-T. Job satisfaction and associated factors among healthcare staff: A cross-sectional study in Guangdong province, China. BMJ Open 2016, 6, e011388. [CrossRef] [PubMed]

40. Xi-Tong, L.; Yi, T.; Xiao-Ni, Z. Job satisfaction level among the public hospital doctors in Chongqing China and its associated factors. J. Epidemiol. Public Health Rev. 2016, 2. [CrossRef]

41. Sun, J.; Ma, J.; Hu, G.; Zhao, Q.; Yuan, C.; Si, W.; Zhang, X.; Liu, Y. Welfare, wellness, and job satisfaction of Chinese physicians: A national survey of public tertiary hospitals in China. Int. J. Health Plan. Manag. 2017, 32, 270-284. [CrossRef] [PubMed]

42. Aidemark, L.G. The meaning of balanced scorecards in the health care organisation. Financ. Account. Manag. 2001, 17, 23-40. [CrossRef]

43. Hsiao, W.C.; Braun, P.; Dunn, D.; Becker, E.R. Resource-based relative values: An overview. JAMA 1988, 260, 2347-2353. [CrossRef] [PubMed]

44. Mohammad Mosadegh Rad, A.; Hossein Yarmohammadian, M. A study of relationship between managers' leadership style and employees' job satisfaction. Leadersh. Health Serv. 2006, 19, 11-28. [CrossRef]

45. Zhang, L.; Stone, T.E.; Zhang, J. Understanding the rise of Yinao in China: A commentary on the little known phenomenon of healthcare violence. Nurs. Health Sci. 2017, 19, 183-187. [CrossRef] [PubMed]

46. Nowrouzi-Kia, B. The impact of workplace violence on health care workers' quality of life. Dev. Med. Child Neurol. 2017. [CrossRef] [PubMed]

47. Schat, A.C.; Frone, M.R. Exposure to psychological aggression at work and job performance: The mediating role of job attitudes and personal health. Work Stress 2011, 25, 23-40. [CrossRef] [PubMed]

48. Sun, N.; Rau, P.-L.P. Barriers to improve physician-patient communication in a primary care setting: Perspectives of Chinese physicians. Health Psychol. Behav. Med. 2017, 5, 166-176. [CrossRef]

49. Ting, X.; Yong, B.; Yin, L.; Mi, T. Patient perception and the barriers to practicing patient-centered communication: A survey and in-depth interview of Chinese patients and physicians. Patient Educ. Couns. 2016, 99, 364-369. [CrossRef] [PubMed]

50. Jiale, H.; Na, L.; Lin, L.; Zhijian, L.; Jin, M. Research on job satisfaction degree of primary healthcare workers after health care system reform in Shanghai city. Chin. Hosp. Manag. 2013, 33, 10-12.

51. Zhang, X.; Fang, P. Job satisfaction of village doctors during the new healthcare reforms in China. Aust. Health Rev. 2016, 40, 225-233. [CrossRef] [PubMed]

52. Li, T.; Lei, T.; Sun, F.; Xie, Z. Determinants of village doctors' job satisfaction under China's health sector reform: A cross-sectional mixed methods study. Int. J. Equity Health 2017, 16, 64. [CrossRef] [PubMed]

53. Kavanaugh, J.; Duffy, J.A.; Lilly, J. The relationship between job satisfaction and demographic variables for healthcare professionals. Manag. Res. News 2006, 29, 304-325. [CrossRef]

54. Salisbury, C.J.; Tettersell, M.J. Comparison of the work of a nurse practitioner with that of a general practitioner. JR Coll. Gen. Pract. 1988, 38, 314-316.

55. Li, L.; Fu, H. China's health care system reform: Progress and prospects. Int. J. Health Plan. Manag. 2017, 32, 240-253. [CrossRef] [PubMed]

56. Liu, G.G.; Vortherms, S.A.; Hong, X. China's health reform update. Annu. Rev. Public Health 2017, 38, 431-448. [CrossRef] [PubMed] 
57. Li, J.; Wang, P.; Kong, X.; Liang, H.; Zhang, X.; Shi, L. Patient satisfaction between primary care providers and hospitals: A cross-sectional survey in Jilin province, China. Int. J. Qual. Health Care 2016, 28, 346-354. [CrossRef] [PubMed]

58. Shan, L.; Li, Y.; Ding, D.; Wu, Q.; Liu, C.; Jiao, M.; Hao, Y.; Han, Y.; Gao, L.; Hao, J. Patient satisfaction with hospital inpatient care: Effects of trust, medical insurance and perceived quality of care. PLoS ONE 2016, 11, e0164366. [CrossRef] [PubMed]

59. García-Alfranca, F.; Puig, A.; Galup, C.; Aguado, H.; Cerdá, I.; Guilabert, M.; Pérez-Jover, V.; Carrillo, I.; Mira, J.J. Patient satisfaction with pre-hospital emergency services. A qualitative study comparing professionals' and patients' views. Int. J. Environ. Res. Public Health 2018, 15, 233. [CrossRef] [PubMed]

2018 by the authors. Licensee MDPI, Basel, Switzerland. This article is an open access article distributed under the terms and conditions of the Creative Commons Attribution (CC BY) license (http://creativecommons.org/licenses/by/4.0/). 